Full length article

\title{
Deformation and degradation of superelastic NiTi under multiaxial loading
}

\author{
Wei-Neng Hsu ${ }^{\text {a, b }}$, Efthymios Polatidis ${ }^{\text {a, }}{ }^{\text {, }}$ Miroslav Šmíd a , Steven Van Petegem a, \\ Nicola Casati ${ }^{c}$, Helena Van Swygenhoven ${ }^{\text {a, b, * }}$ \\ a Photons for Engineering and Manufacturing Group, Photon Science Division, Paul Scherrer Institute, 5232, Villigen-PSI, Switzerland \\ ${ }^{\mathrm{b}}$ Neutrons and X-rays for Mechanics of Materials, Institute of Materials, Ecole Polytechnique Fédérale de Lausanne, 1015, Lausanne, Switzerland \\ ${ }^{c}$ Materials Science Group, Photon Science Division, Paul Scherrer Institute, 5232, Villigen-PSI, Switzerland
}

\section{A R T I C L E I N F O}

\section{Article history:}

Received 29 November 2018

Received in revised form

25 January 2019

Accepted 26 January 2019

Available online 30 January 2019

\section{Keywords:}

Superelastic NiTi

Multiaxial

Load path change

Martensitic transformation

Functional fatigue

\begin{abstract}
A B S T R A C T
The degradation of the superelastic properties of a commercial NiTi alloy is studied during uniaxial, biaxial and load-path-change cycling performed in-situ with synchrotron X-ray diffraction. Careful examination of the diffraction pattern during uniaxial loading shows the R-phase as a transition between the austenite and the B19' martensite. Degradation of the superelasticity is found to depend strongly on the loading and unloading path followed, and it is discussed in terms the B19' martensitic variant selection, the accumulation of dislocations, and the residual R-Phase and B19' martensite. Cycling biaxially leads to faster degradation than uniaxially due to a larger accumulation of dislocations. If the deformation cycle contains a load path change, dislocation accumulation increases further and more martensite is retained.
\end{abstract}

(C) 2019 Acta Materialia Inc. Published by Elsevier Ltd. This is an open access article under the CC BY-NCND license (http://creativecommons.org/licenses/by-nc-nd/4.0/).

\section{Introduction}

The superelasticity of NiTi alloys enables the material to sustain large strains thanks to the reversible deformation-induced martensitic transformation. Under an external load, the material transforms from the austenite B2 crystal structure to the B19' martensite phase [1,2]. Once the load is removed, the material returns to its original shape as martensite fully transforms back to austenite. This unique property has found applications in biomedical engineering such as in endovascular stents, cardiovascular stents and orthopaedic devices [3]. These components made of superelastic (SE) NiTi experience multiaxial deformation in vivo $[4,5]$. Hence, it is important to study the martensitic transformation under multiaxial deformation or load path changes. It has been shown that uniaxial compression exhibits a smaller recoverable strain than uniaxial tension, a steeper transformation stress-strain slope and a higher critical stress for martensitic transformation

\footnotetext{
* Corresponding author. Photons for Engineering and Manufacturing Group Photon Science Division, Paul Scherrer Institute, 5232, Villigen-PSI, Switzerland. E-mail address: helena.vanswygenhoven@psi.ch (H. Van Swygenhoven).

1 Currently in Laboratory for Neutron Scattering and Imaging (LNS), Paul Scherrer Institute, 5232 Villigen-PSI, Switzerland.
}

[6-8]. A limited number of studies on the effect of load path changes can be found. Upon changing the loading path from tension to torsion, McNaney et al. reported two distinct plateau regions in the stress-strain curve, which was attributed to different martensite variants associated with different load paths [9]. Combining high-resolution digital image correlation (HRDIC) and in-situ X-ray diffraction (XRD) during one loading cycle, it was shown how strain was accommodated by selecting different martensitic variants [10].

Structural and functional stability upon cyclic deformation are required for biomedical applications, i.e. structural fatigue leads to mechanical failure, and functional fatigue results in the degradation of the SE properties [11,12]. Fatigue has been shown to lead to a reduction of the critical stress required for the transformation from austenite to martensite, accumulation of permanent deformation [13-17], appearance of the intermediate rhombohedral R-phase martensite $[18,19]$ and decrease in the dissipated energy of the transformation cycle $[14,17,20-25]$. The resistance of the SE NiTi to functional fatigue depends on the crystallographic texture and the presence of precipitates [26], the austenite grain size [27-29], the loading rate $[30,31]$ and the testing temperature [25]. To date, there are only few studies addressing the effect of multiaxial or loadpath-change cycling on the degradation of SE NiTi. Song et al. 
performed non-proportional tension-torsion cyclic tests on SE NiTi tubes and reported that multiaxial stress states lead to faster accumulation of residual strain, compared to uniaxial loading [32]. Among most multiaxial studies mentioned above, the transformation behavior and the material degradation were examined only at the macroscopic length scale. Khodaei et al. showed that constitutive modelling failed to predict the mechanical response under multiaxial loads, because the model does not capture the anisotropic transformation behaviour related to the crystallographic orientation and the loading path [33]. Detailed experimental data is required to improve the micromechanical models.

Combining cruciform multiaxial mechanical tests with in-situ synchrotron XRD, employing a miniaturized biaxial device for application of in-plane biaxial loads and load path changes, the microstructural evolution of a commercial SE NiTi during multiple cycling is studied. The microstructural degradation induced by multiaxial and load-path-change cycling are reported.

\section{Experimental}

SE NiTi sheet with a thickness of $150 \mu \mathrm{m}$ was purchased from Memry GmbH. The optimized cruciform geometry with a central pocket is shown in Fig. 1. The gradual thinning from $150 \mu \mathrm{m}$ (arm) down to $50 \mu \mathrm{m}$ (central pocket) allows the martensitic transformation to occur at the center of the cruciform where the synchrotron X-ray investigation is positioned. The rounded-square pockets were fabricated by electrochemical micromachining (ECMM), carried out at micropat SA, Switzerland. After introducing the pockets to both sides of the sheet by ECMM, the outline of the cruciform was cut with an Nd:YAG picosecond pulsed laser at the Swiss Federal Laboratories for Materials Science and Technology (EMPA). A detailed description regarding the cruciform sample preparation can be found in Ref. [34]. The microstructure at the center of the cruciform was investigated with Electron Backscatter Diffraction (EBSD) using a field emission gun scanning electron microscope (FEG SEM) Zeiss ULTRA 55 equipped with EDAX Hikari Camera operated at $20 \mathrm{kV}$ in high current mode with the $120-\mu \mathrm{m}$ aperture and a step size of $90 \mathrm{~nm}$. The post processing of the EBSD data was done with the EDAX OIM Analysis 7.3 software.

The four load paths studied in this work are illustrated in Fig. 2: uniaxial (UN), equibiaxial (EQ), triangular (TR) and square (SQ). The deformation tests were performed on the cruciform samples employing an upscale version of the minibiax tensile machine [35], hereafter called the meso biaxial tensile machine. The device has a very similar setup as the minibiax but a higher load capacity up to $1000 \mathrm{~N}$. More details about the machine parameters can be found in the supplementary material. For each load path, 100 displacement-

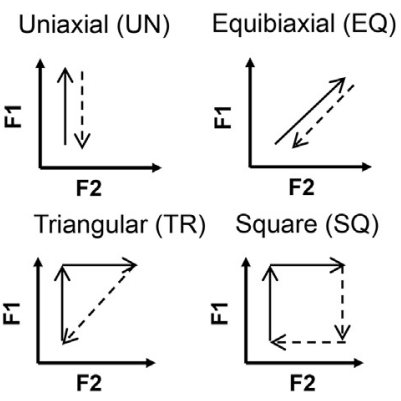

Fig. 2. The four load paths applied to the cruciform samples. The solid lines represent the loading steps; the dashed-lines represent the unloading paths.

controlled mechanical cycles were performed, 9 cycles $\left(1^{\text {st }}, 5^{\text {th }}, 10^{\text {th }}\right.$, $15^{\text {th }}, 20^{\text {th }}, 30^{\text {th }}, 40^{\text {th }}, 60^{\text {th }}$ and $\left.100^{\text {th }}\right)$ were followed with in-situ XRD measurements. The in-situ cycles were performed with a displacement rate of $0.2 \mu \mathrm{m} / \mathrm{s}$; the cycles in between (non-in-situ cycles) were done with a displacement rate of $2 \mu \mathrm{m} / \mathrm{s}$. Preliminary tests showed that the transformation occurs at different displacements upon loading along the two in-plane directions of the cruciform i.e. the F1 and F2 direction. For all the load paths shown in Fig. 2, the displacements reached along the F1 and F2 direction were $131 \mu \mathrm{m}$ and $150 \mu \mathrm{m}$, ensuring the occurrence of martensitic transformation.

The meso biaxial tensile machine was mounted on the goniometer of the Materials Science (MS) X04SA beam line at the Swiss Light Source (SLS) [36]. Similar to the experimental setup in Ref. [10], the experiments were carried out in transmission with a $20 \mathrm{keV}$ beam and a $70 \times 70 \mu \mathrm{m}^{2}$ spot size probing the center of the cruciform. The diffraction data along the scattering vectors parallel to the two inplane F1 and F2 directions of the cruciform were recorded by two detectors with $30 \mathrm{~s}$ counting time. The Mythen II microstrip detector recorded the diffraction data parallel to $\mathrm{F} 1$ in a range of $2 \theta$ of $\sim-55^{\circ}$ to $+55^{\circ}$. The $2 \mathrm{D}$ data from Pilatus was caked and integrated using FIT2D [37] along an azimuthal range of $175^{\circ}-185^{\circ}$, corresponding to the direction parallel to $\mathrm{F} 2$. $\mathrm{LaB}_{6}$ was used as the reference material for the calibration of the detector position, the tilt and rotation angles and the beam center. The single peak fitting of the diffraction data was done with pseudo-Voigt functions using an in-house code in MATLAB. Unless stated, the diffraction data shown hereafter were obtained with the Mythen II detector.

\section{Results}

\subsection{R-phase martensitic transformation}

Fig. 3a $-3 c$ show EBSD orientation maps of the center of the

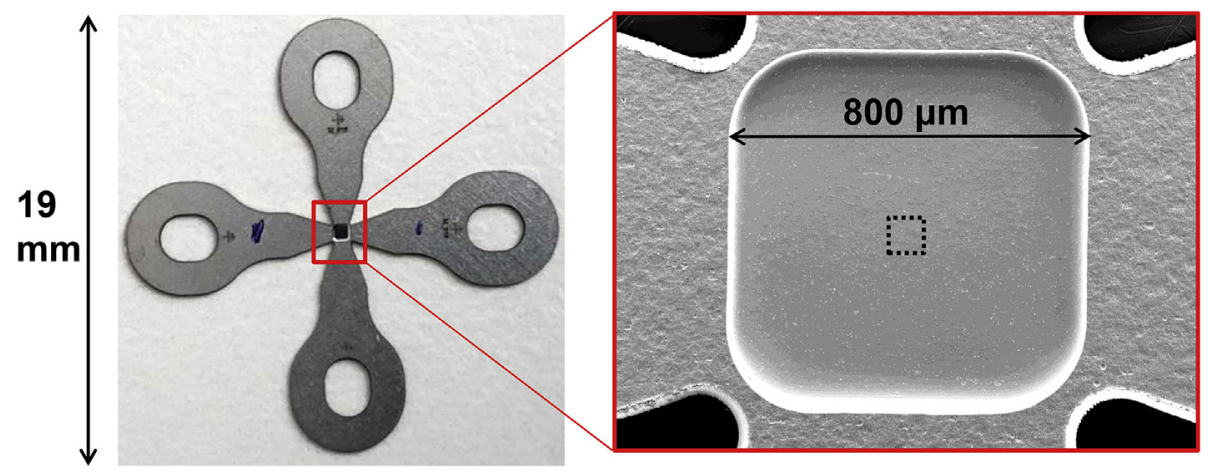

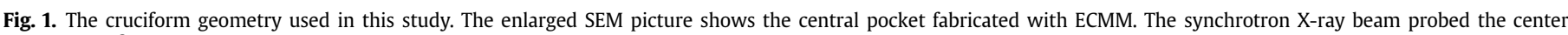
$\left(\sim 70 \times 70 \mu \mathrm{m}^{2}\right)$ of the pocket indicated by the dashed line. 
ND

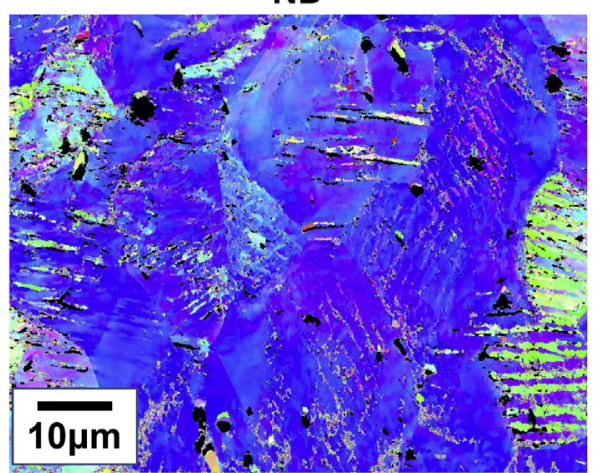

F2 direction

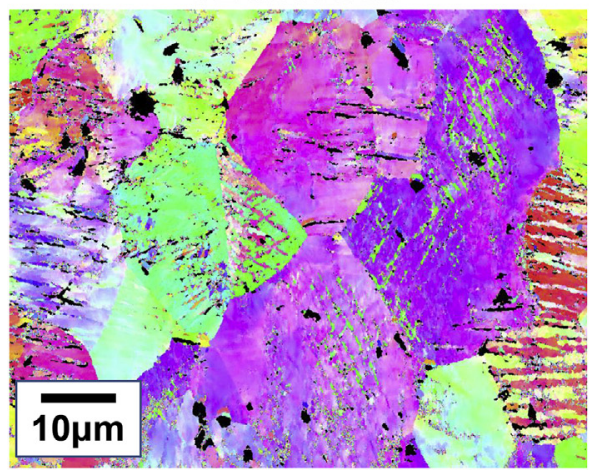

F1 direction
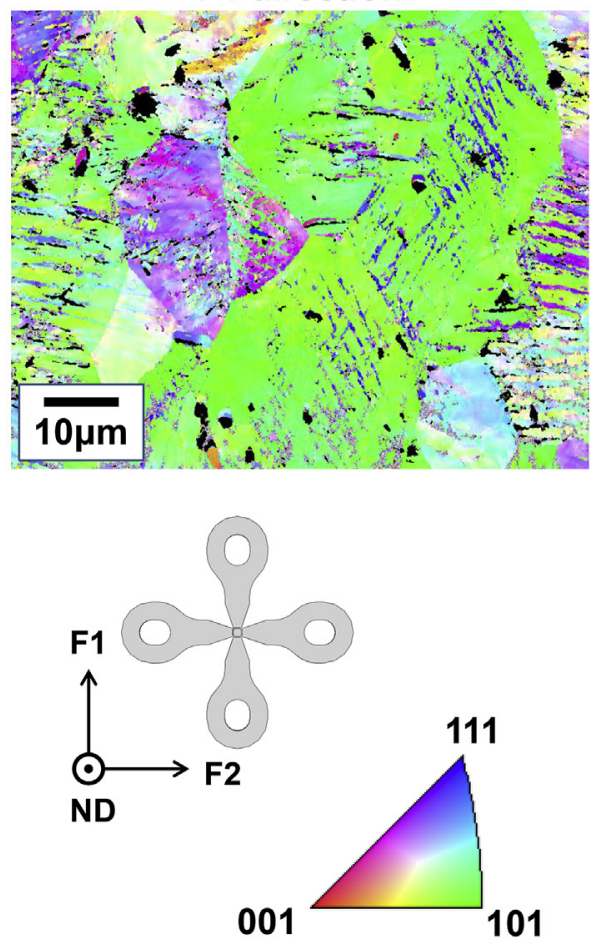

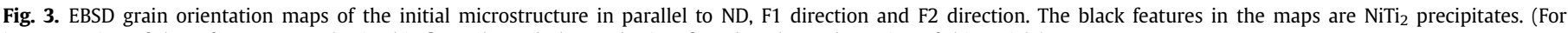
interpretation of the references to color in this figure legend, the reader is referred to the Web version of this article).

cruciform (field of view of $72 \mu \mathrm{m} \times 57 \mu \mathrm{m}$ ) taken parallel to the sample normal (ND), F1 and F2 respectively. The majority of the grain orientations in the field of view shows a strong $<111>$ texture parallel to ND and $<101>$ parallel to F1. A previous study has shown that the grains consist of fine austenite subgrains $(\sim 40 \mathrm{~nm})$ which transform collectively into the B19' martensite phase upon mechanical loading [10]. Fig. $4 a-c$ presents the in-situ XRD spectra for different $2 \theta$ ranges and the force-displacement curve upon loading (Fig. 4d). As shown in Fig. 4b and c, the (2 -2 $2)_{R}$ and $(01-2)_{R}$ peaks appear when the sample is loaded up to $9.4 \mathrm{~N}$. These peaks continue to grow as the loading proceeds. The Rphase peaks reach maximum intensities at $15.3 \mathrm{~N}$ after which they start to decrease in intensity upon further loading. Meanwhile, a drastic intensity drop of the $\left(\begin{array}{lll}1 & 1 & 0\end{array}\right)_{\mathrm{B} 2}$ peak accompanied with the growth of the $\left(\begin{array}{lll}0 & 0 & 2\end{array}\right)_{\text {B19' }}$ peak can be seen in Fig. 4a. Fig. $4 \mathrm{~b}$ also shows the decreasing intensity of the $(2-22)_{R}$ peak and the growth of the $\left(\begin{array}{lll}0 & 1 & 2\end{array}\right)_{\mathrm{B} 19^{\prime}} /\left(\begin{array}{lll}1 & 1 & 1\end{array}\right)_{\mathrm{B} 19^{\prime}}$ peaks (two nearly overlapping B19' peaks) at forces larger than $15.3 \mathrm{~N}$. The decrease in the slope of the force-displacement curve, as shown in Fig. $4 \mathrm{~d}$, is due to the formation of the B19' martensite. The material predominantly transforms into the B19' martensite when the force reaches $20.9 \mathrm{~N}$, at which the $\left(\begin{array}{lll}1 & 1 & 0\end{array}\right)_{\mathrm{B} 2}$ peak becomes weak and the R-phase peaks nearly disappear. In other words the material transforms from $\mathrm{B} 2$ to B19' via an intermediate R-phase. The transformation via R-phase was not reported in Ref. [10]; however, careful examination made us realizing that we overlooked the presence, probably because no remaining R-phase is observed after unloading of one cycle.

\subsection{Martensitic variants at different loading directions}

The formation and selection of the B19' martensite variants depend strongly on the loading direction. Fig. 5 shows the diffraction spectra captured at the maximum load of three different monotonic loadings: uniaxial along F1 (UN F1), uniaxial along F2 (UN F2) and equibiaxial (EQ F1F2). The highest intensities are

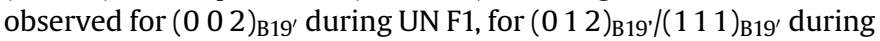
UN F2 and for (11 -1 $)_{\mathrm{B} 19^{\prime}}$ during EQ F1F2. Additionally, the (11 10$)_{\mathrm{B} 19^{\prime}}$ peak is observed in UN F2 whereas not in UN F1. These results demonstrate that different sets of martensite variants form when the cruciform is loaded along different directions. The different sets of martensite variants are hereafter denoted as VF1, VF1F2 and VF2.

We now look at the effect of a load path change. Fig. 6a compares the diffraction spectra captured at two loading conditions during the first TR cycle: at F1max (F1: 27N) and after the load path change to F1F2 (F1: 33N, F2: 42N). When the loading condition is changed from F1max to F1F2, the intensity of the $\left(\begin{array}{lll}0 & 0 & 2\end{array}\right)_{\mathrm{B} 19^{\prime}}$ peak decreases meanwhile the $\left(\begin{array}{ll}11 & -1\end{array}\right)_{\mathrm{B} 19^{\prime}}$ and $\left(\begin{array}{lll}0 & 12\end{array}\right)_{\mathrm{B} 19^{\prime}} /\left(\begin{array}{lll}1 & 11\end{array}\right)_{\mathrm{B} 19^{\prime}}$ peaks grow. Fig. $6 \mathrm{~b}$ focuses on the formation of the $(11-1)_{\mathrm{B} 19}$, when going from F1max to F1F2 and demonstrates the growth of the $\left(\begin{array}{lll}1 & 1 & 0\end{array}\right)_{\mathrm{B} 2}$ peak during the load path change. In other words, changing the load path from uniaxial to biaxial induces changes in martensite variants as well as the reverse transformation from martensite back to austenite, as already suggested in Ref. [10].

\subsection{Multiaxial mechanical cycles}

Fig. 7 plots the force-displacement curves for the uniaxial cycles and particularly those that were performed in-situ (i.e. cycle 1, 5, 10 ..100). The critical force for transformation decreases with the increasing number of cycles, as apparent from the change of the slope of the force-displacement curve and the force drop. Fig. 7 also shows the development of residual displacement and the decrease in the dissipated energy (area enclosed by the SE loop) after uniaxial cycling. It has to be noted that the interpretation of the 
(a)

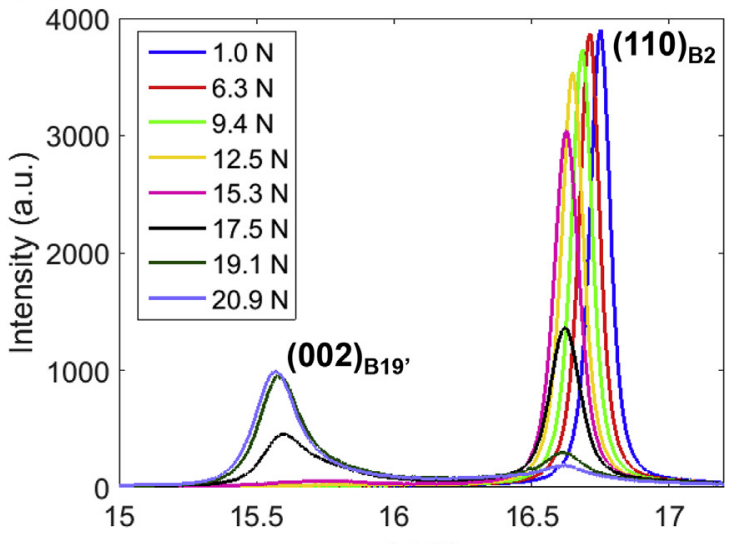

(c)

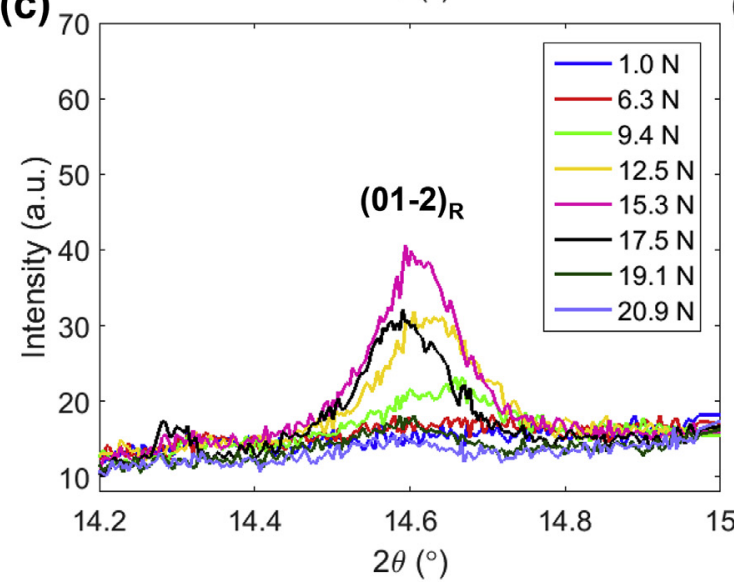

(b)

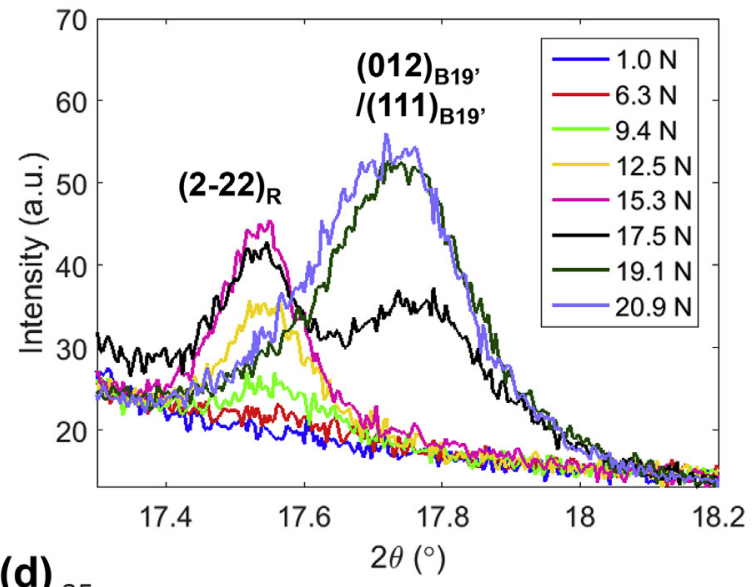

(d)

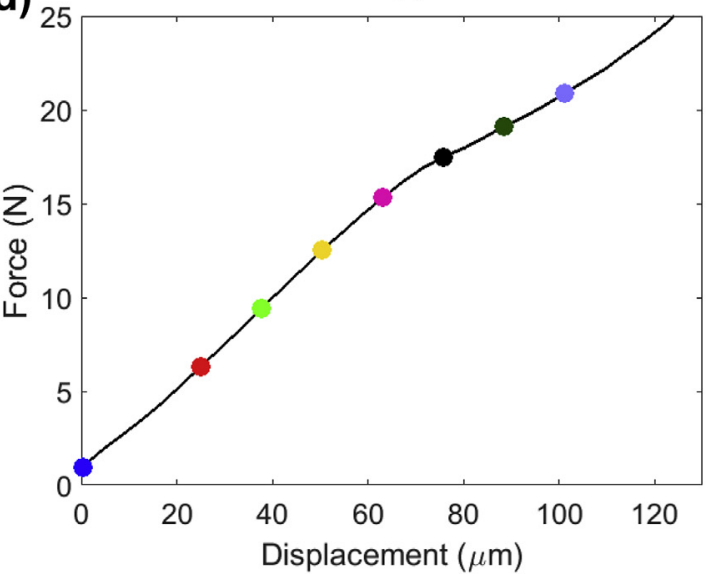

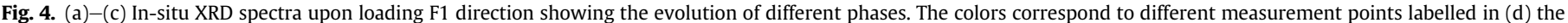
force-displacement curve.

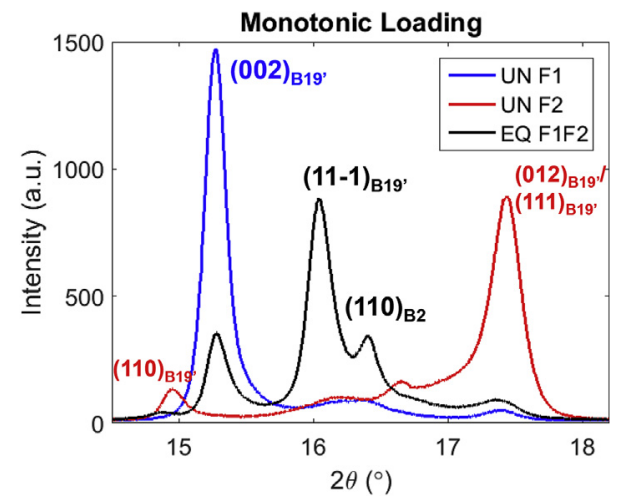

Fig. 5. Different martensite peaks (corresponding to different variants) observed under monotonic loadings: uniaxial along F1 direction (UN F1), uniaxial along F2 direction (UN F2) and equibiaxial load (EQ F1F2).

mechanical data from the cruciform tests is not as straightforward as from the uniaxial dogbone tests since stress concentration and martensitic transformation occur also outside the thinned cruciform area. Therefore, the macroscopic mechanical data represents a convolution of deformation inside and outside the thinned area probed by X-rays.

We define a critical transformation force as the force corresponding to a reduction of $80 \%$ of the maximum intensity of the (11
$0)_{\mathrm{B} 2}$ peak, and for which meanwhile, the martensite peaks start to become apparent in the diffraction patterns. Fig. 8 shows that multiaxial cycling (SQ TR and EQ) decreases the critical transformation force faster than UN cycling. SQ and TR result in larger reduction in the critical transformation force compared to the monotonic EQ cycling. Fig. 9 compares the in-situ XRD spectra of loading in the F1 direction during the TR cycle 1 and 10. It clearly shows that the B19' martensitic transformation occurs at lower force as the cycling advances. Furthermore, the $\left(\begin{array}{lll}0 & 0 & 2\end{array}\right)_{\mathrm{B} 19^{\prime}}$ peak appears after $16.2 \mathrm{~N}$ during cycle 1 (see Fig. 9a), whereas during cycle 10 , the $\left(\begin{array}{lll}0 & 0 & 2\end{array}\right)_{\mathrm{B} 19^{\prime}}$ peak can be observed already at $12.5 \mathrm{~N}$ (see Fig. 9c). Apart from the B19' martensitic transformation, the mechanical cycles also facilitate the formation of R-phase martensite. During the first cycle, the $(1-24)_{\mathrm{R}}$ peak does not appear. However at cycle 10 shown in Fig. 9d, the $(1-24)_{R}$ peak becomes apparent next to the $(211)_{\mathrm{B} 2}$ after reaching $8.5 \mathrm{~N}$. As the loading continues, both $(1-24)_{R}$ and $(211)_{B 2}$ peaks decrease in intensity, meanwhile the (lo 02$)_{\text {B19' }}$ peak grows significantly.

The degradation induced by the mechanical cycles is also manifested by the broadening of the XRD peaks due to accumulation of dislocations. Fig. 10 compares the broadening of the $(110)_{\mathrm{B} 2}$ peak during different types of cycles. The full-width-at-halfmaximum (FWHM) of $\left(\begin{array}{lll}1 & 1 & 0\end{array}\right)_{\mathrm{B} 2}$ increases significantly more under multiaxial cycling than uniaxial cycling. The strongest austenite peak, $\left(\begin{array}{lll}1 & 1 & 0\end{array}\right)_{\mathrm{B} 2}$, broadens the most after the SQ cycles, followed by the TR cycles and the EQ cycles. Although the data from the Pilatus detector is available only until the $40^{\text {th }}$ SQ cycle, it is evident that SQ 
(a)

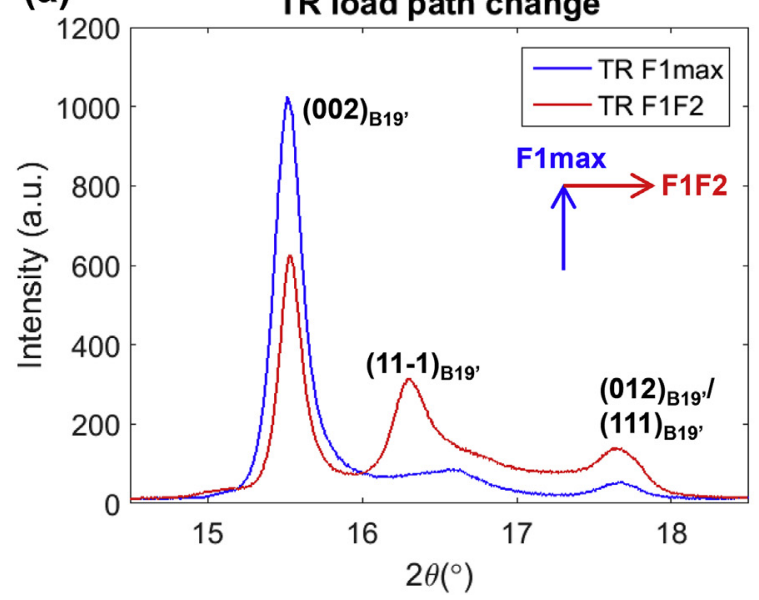

(b)

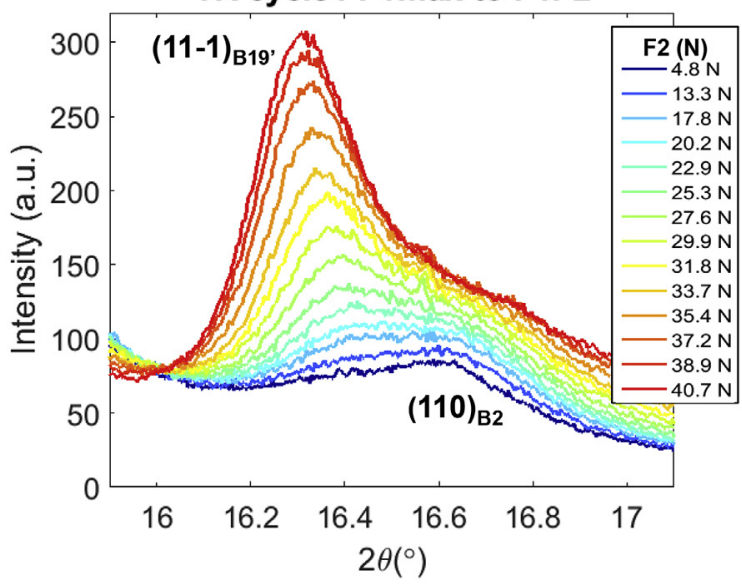

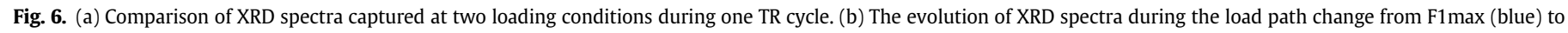
F1F2 (red).

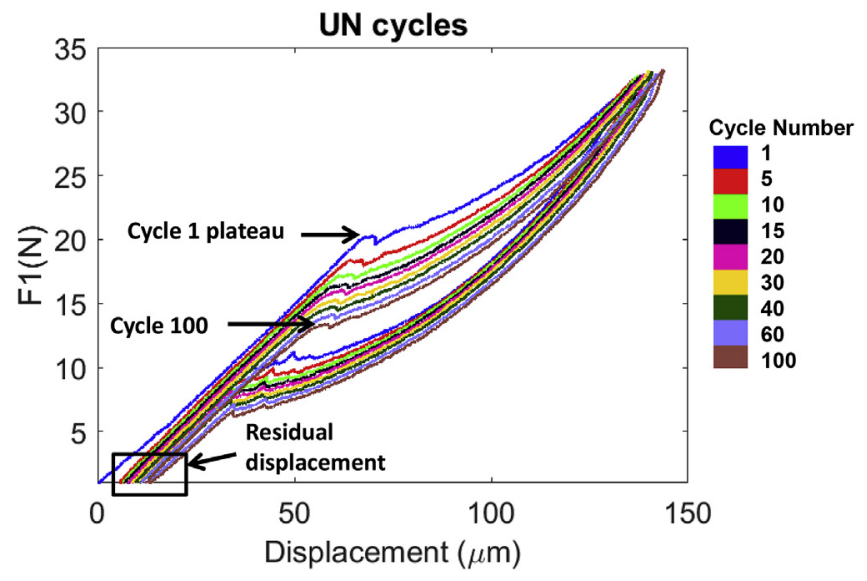

Fig. 7. The force-displacement curves of the in-situ uniaxial cycles show typical behavior of superelastic NiTi under cycling.

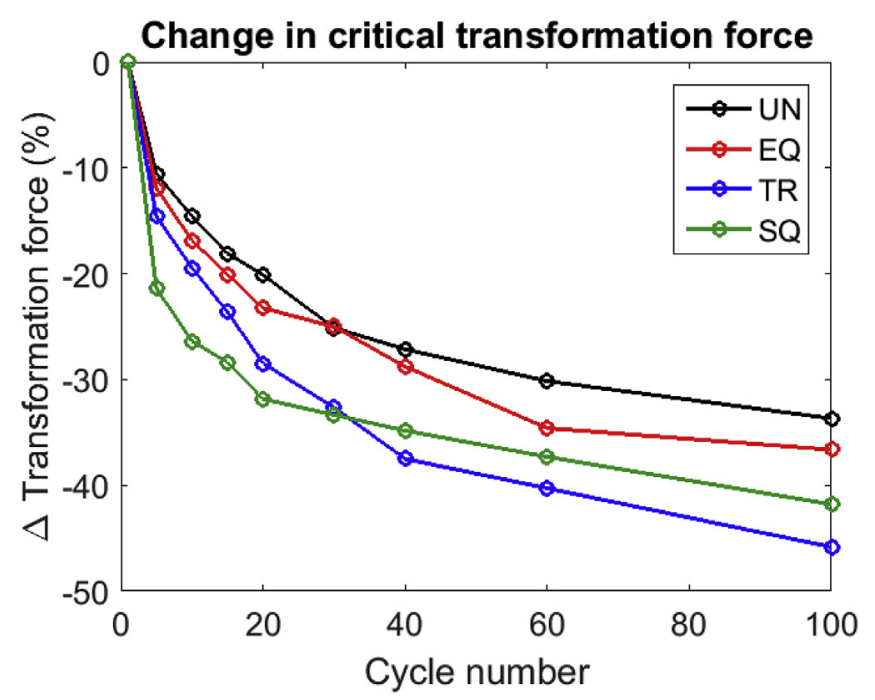

Fig. 8. Evolution of the critical transformation force as a function of the number of cycles. produces the most pronounced broadening. The broadening of the second strongest austenite peak, (2 111$)_{\mathrm{B} 2}$, follows the same trend albeit not shown here. These findings imply that multiaxial cycling accumulates more dislocations than uniaxial cycling.

Another characteristic of SE degradation induced by mechanical cycling is the accumulation of retained martensite since the material is no longer able to transform fully back to austenite when removing the external load. The retained martensite found after mechanical cycling also contributes to the accumulation of residual strain. Fig. 11 presents the evolutions of the retained martensite after different types of cycling. The retained $(2-22)_{R}$ peak can be observed in all load paths after 100 cycles, but it is less pronounced in the monotonic load-unload cycling (UN and EQ). TR results in the growth of retained $\left(\begin{array}{lll}0 & 0 & 2\end{array}\right)_{\mathrm{B} 19^{\prime}}$ peak. As for SQ, the $\left(\begin{array}{llll}0 & 0\end{array}\right)_{\mathrm{B} 19^{\prime}}$ and (1 11 $-1)_{\mathrm{B} 19}$, peaks are present in the diffraction patterns after cycling and unloading. Fig. 11 highlights the importance of both loading and unloading paths in the development of retained martensite. Reaching F1F2 via a load path change (TR cycles) results in more retained martensite than monotonic equibiaxial loading (EQ cycles). Despite the same loading sequence for TR and SQ the different unloading sequences develop different retained martensite peaks.

\section{Discussion}

\subsection{Materials degradation induced by mechanical cycles}

The degradation in the superelasticity i.e. the decrease in the critical transformation force can be attributed to the increasing dislocation density as cycling proceeds, as witnessed by the broadening of the B2 austenite peaks. Transmission electron microscope (TEM) studies have reported that the forward martensitic transformation accompanies the creation of dislocations, which retain in the austenite phase after reverse transformation [38-40]. The accumulation of dislocations induced by mechanical cycling, as evidenced by TEM in Refs. [18,26,27,41,42], contribute to the residual strain in the austenite phase. In addition, the dislocations retained in the austenite phase facilitate the nucleation of B19' martensite: the stress fields around dislocations decrease the external work required for the stress-induced martensitic transformation [17], i.e. decreasing the required transformation force as observed in Fig. 8. The dislocations introduced by cycling are also essential for promoting the R-phase transformation [43-45]. 
(a)

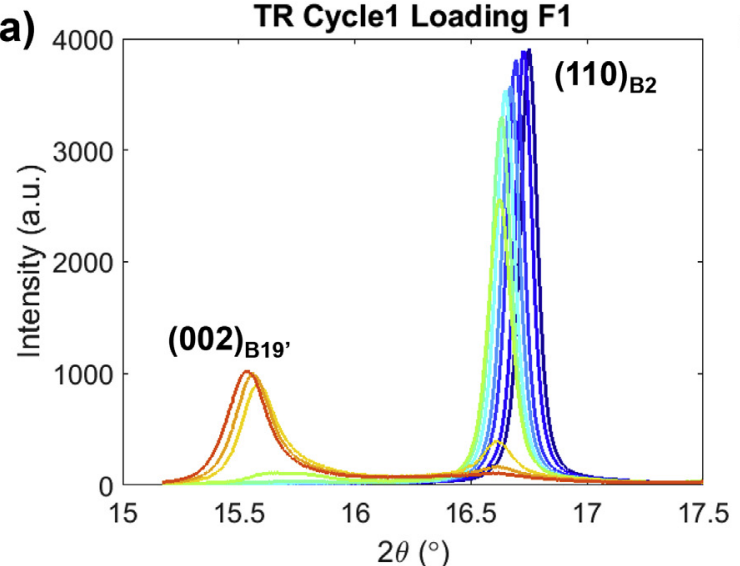

(c)

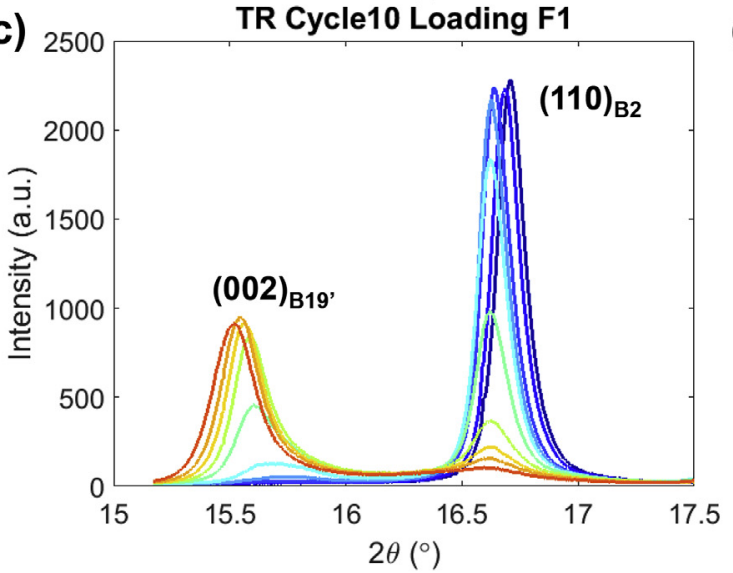

(b)

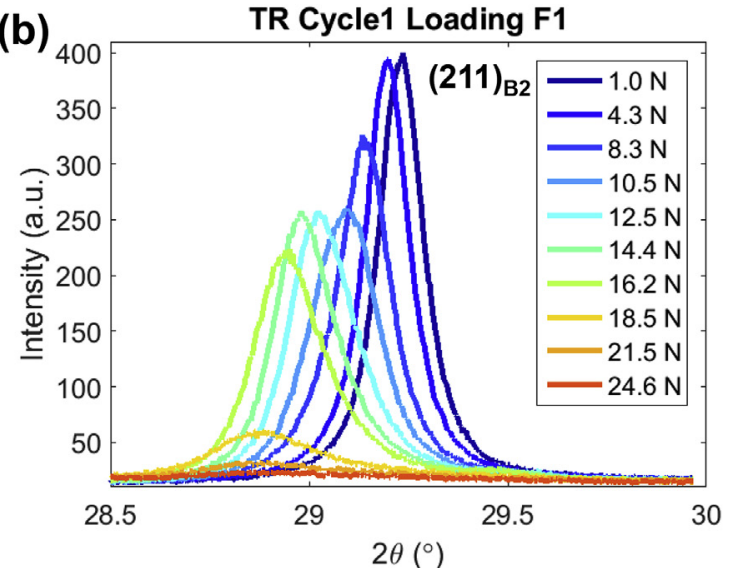

(d)

TR Cycle10 Loading F1

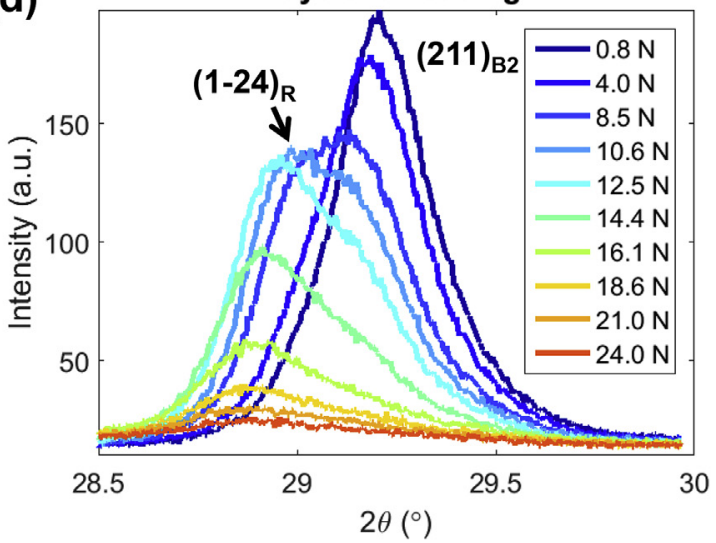

Fig. 9. The evolution of the XRD spectra during loading F1 in the (a)-(b) $1^{\text {st }}$ TR cycle, and (c) $-(d) 10^{\text {th }}$ TR cycle.
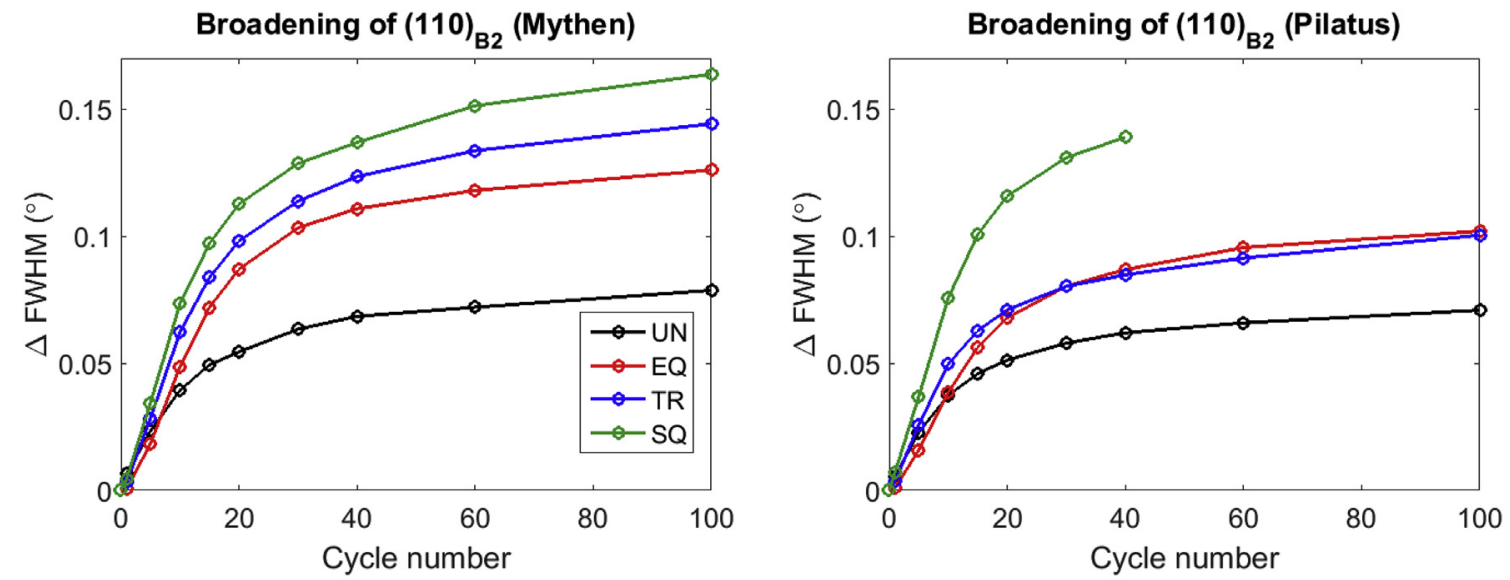

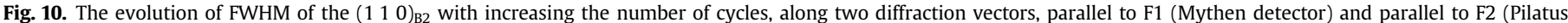
detector) for different loading paths.

Consequently, the mechanical cycling lowers the transformation force for R-phase martensite, as exemplified by Fig. 9b and d.

It is worth noting that both the decrease in the transformation force and the peak broadening slow down after 20 cycles, i.e. the degradation in SE properties tends to reach a saturation with increasing number of cycles. Such saturation has also been reported in the literature, and it is due to the steady-state dislocation structure which is difficult to change with further cycling $[17,46,47]$.

\subsection{Monotonic load-unload cycles: EQ and UN cycles}

The present study shows the dependency of SE degradation on the loading path. Multiaxial mechanical cycling (SQ TR and EQ) is found to degrade the SE NiTi faster than uniaxial cycling. One question that comes up from these results is: why does EQ cycling degrade the material more than UN cycling? The UN cycles were conducted by loading the cruciform along the F1 direction. As for the EQ cycles, two in-plane loads along the directions F1 and F2 

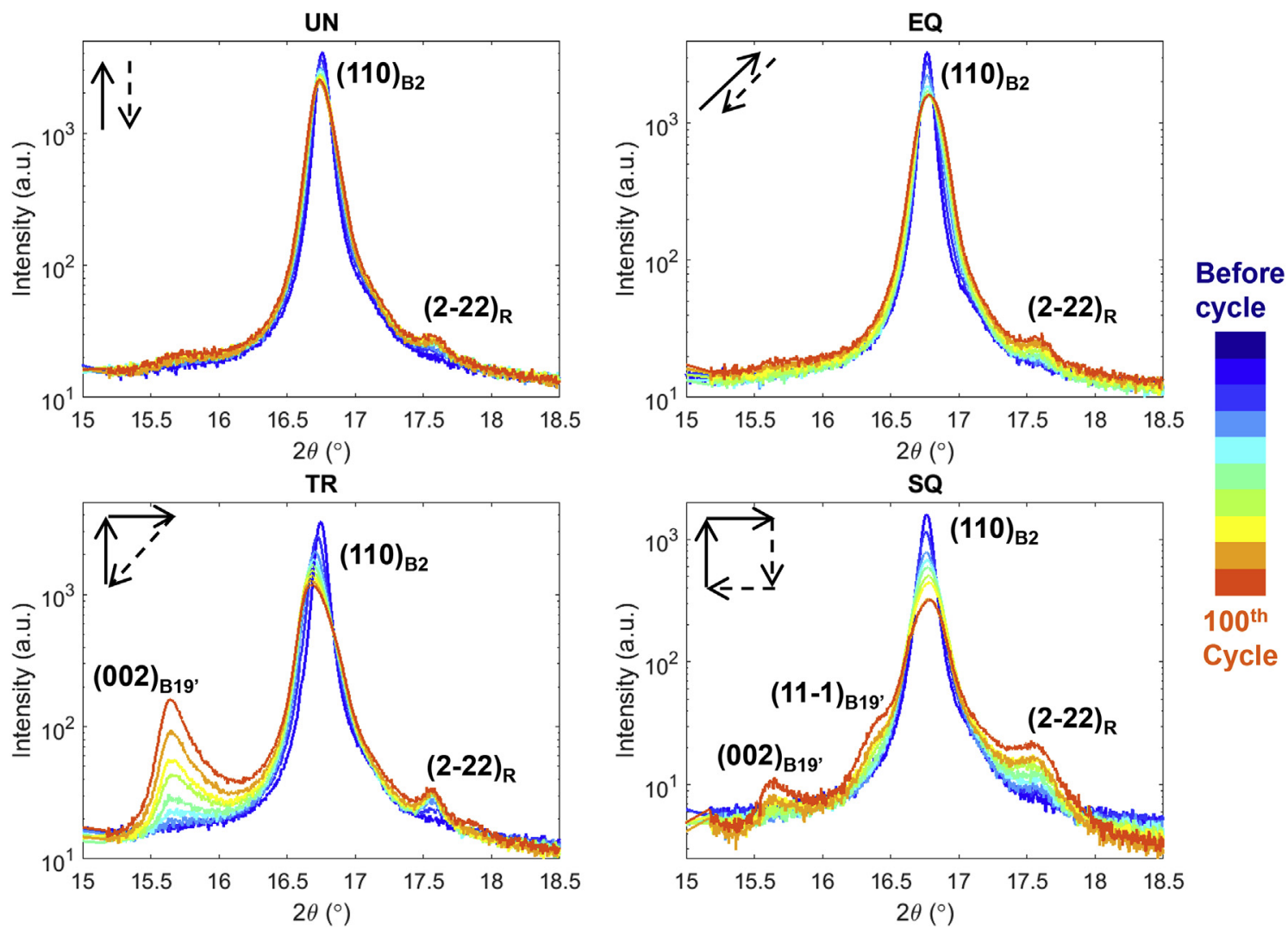

Fig. 11. Diffraction patterns showing the evolution of retained marteniste and R-phase under different loading paths.

were simultaneously applied to the cruciform. Since in-plane equibiaxial loading has the same normalized strain tensor as uniaxial compression along the direction perpendicular to the sample surface, i.e. ND [48], the comparison is now between uniaxial compression along ND and uniaxial tension along the F1 direction. The martensitic transformation in NiTi depends on both the loading state (tension or compression) and the austenite crystallographic orientation, showing large anisotropy in the transformation strain. Lattice deformation calculations for single crystals have shown that uniaxial compression along [111]-oriented austenite generates the lowest transformation strain $[49,50]$, implying that this crystallographic orientation exhibits poor SE properties and the imposed strain is accommodated by transformation but also by dislocations multiplication and slip. Poor superelasticity with large irreversible strain and high cyclic instability, due to a significant increase in dislocation density, have been observed in [ [ 111 1]-oriented austenite grains under uniaxial compression [51]. The same calculations showed that uniaxial tension along [ $\left.\begin{array}{lll}1 & 0 & 1\end{array}\right]$ can result in more than $8 \%$ transformation strain [50], suggesting that solely the martensitic transformation is able to accommodate high strains induced by the applied load. Assuming that the crystallographic responses of a single crystal and a highly textured polycrystalline NiTi are comparable [52], the difference in EQ and UN can be explained by the texture shown in Fig. 3. Owing to the strong $<1$ $01>/ / F 1$ direction texture, UN exhibits better superelasticity as large strain could be accommodated solely by the formation of martensite. On the other hand, EQ (uniaxial compression along the $<111>$ texture) would exhibit more dislocation slip activity in addition to the martensitic transformation. This explains also the difference in residual peak broadening in the austenite: more dislocations accumulate during the EQ cycling compared to the UN cycling. These results demonstrate that the initial austenite texture and the load path influence the SE degradation. Avoiding $<111>$ out-of-plane texture would reduce the microstructural degradation during in-plane-equibiaxial cycling.

\subsection{Load-path-change cycles: SQ and TR cycles}

The load-path-change cycles SQ and TR degrade the material faster than the monotonic load-unload cycling EQ and UN. Both loading and unloading paths affect the degradation. Fig. 12 summarizes the possible deformation mechanisms during each load path for both TR and SQ cycles.

For the TR load path, the majority of the austenite grains (denoted as A in Fig. 12) transforms into a set of martensite variants (VF1) upon loading F1. There are still untransformed austenite grains after reaching F1max, as reported in Ref. [10]. Additionally, the change in loading condition from F1max to F1F2 can induce the reverse transformation as evidenced by the growth of the $\left(\begin{array}{ll}1 & 10\end{array}\right)_{\mathrm{B} 2}$ peak in Fig. 6b. Since the material is mostly in the martensite phase (VF1) at F1max, the subsequent loading along the F2 direction deforms the pre-existing VF1 martensite. In Refs. [53,54], it is seen that martensite can exhibit reorientation/detwinning and formation of dislocations depending on the loading direction. Taking these mechanisms into account, the VF1 martensite undergoing loading along F2 (towards F1F2) can exhibit simultaneously: (1) reorientation/detwinning into VF1F2 variants (denoted as VF1 - > VF1F2 in Fig. 12), (2) plastic deformation generating dislocations (denoted as VF1+dislocations in Fig. 12), and (3) reverse transformation (denoted as VF1 ->A in Fig. 12). Note that VF1 likely contains more dislocations than VF1F2 since it undergoes plastic deformation. Moreover, some of the untransformed austenite at F1 max can transform into VF1F2 upon loading F2 (denoted as A - > VF1F2 in Fig. 12), contributing to the VF1F2 footprint. It is 
\begin{tabular}{|l|l|l} 
Loading F1 & \multicolumn{1}{|c|}{ Loading F2 } & Unloading F1\&F2 \\
& &
\end{tabular}

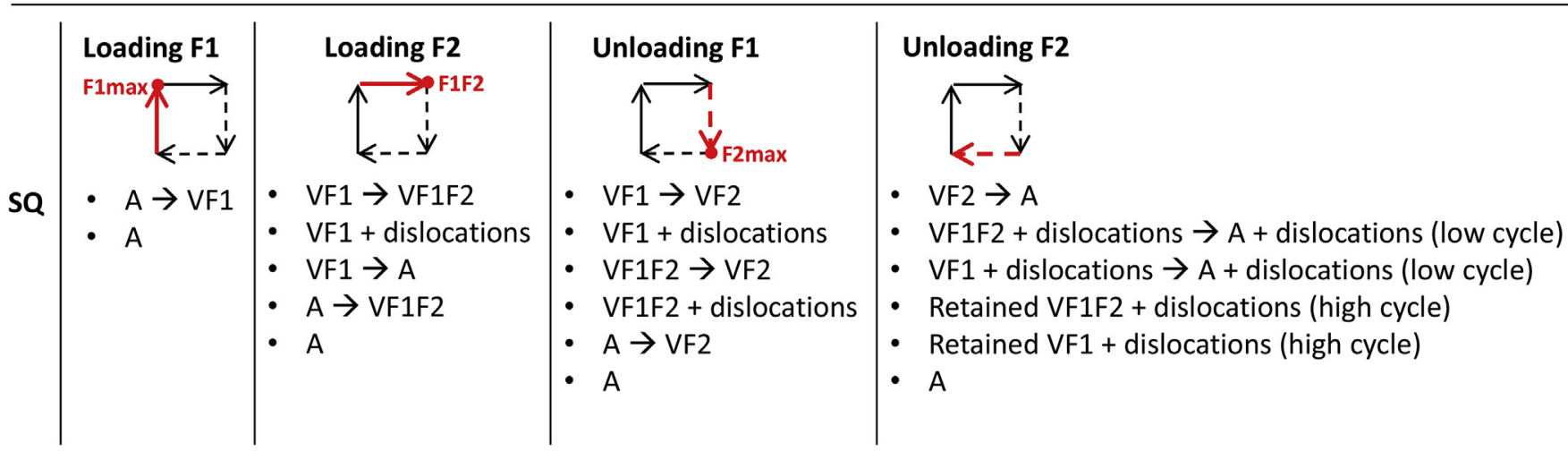

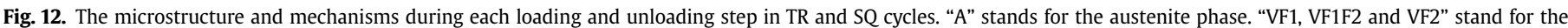

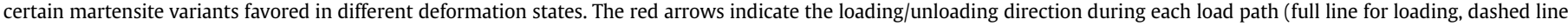
for unloading). (For interpretation of the references to color in this figure legend, the reader is referred to the Web version of this article.)

possible that some austenite grains still stay untransformed. The last step in one TR cycle is unloading the material along F1 and F2 directions simultaneously. For a low number of cycles, the full reverse transformation is observed. The dislocations created upon the load path change remain in the material and result in the broadening of the austenite peaks. For a high number of cycles, the accumulation of dislocations creates local stress fields that stabilize the martensite, seen as retained martensite in Fig. 11. Based on the deformation mechanisms proposed above, VF1 accumulates more dislocations than VF1F2 after cycling, resulting in more retained VF1 martensite. As shown in Fig. 11, the TR cycles result in a strong retained $\left(\begin{array}{lll}0 & 0 & 2\end{array}\right)_{\mathrm{B} 19}$, peak, which agrees with the martensite footprint VF1 shown in Fig. 5.
In contrast to TR, SQ contains two unloading paths: F1 is unloaded before unloading F2. The first unloading along the F1 direction changes the deformation from the F1F2 state to the F2max state. As the cruciform is still loaded in the F2 direction, the center of the cruciform that contains both VF1 and VF1F2 continues to experience additional deformation as witnessed by the shift in the peak position. Similar to the above discussion, VF1 may reorient into the VF2 martensite favored by the F2max state or accommodate the deformation by creating dislocations. In order to investigate the effect of unloading along the F1 direction on the VF1F2 martensite, an additional load-path-change experiment has been done: a cruciform was directly loaded to F1F2 condition, followed by unloading along the F1 direction. Fig. 13 shows the evolution of

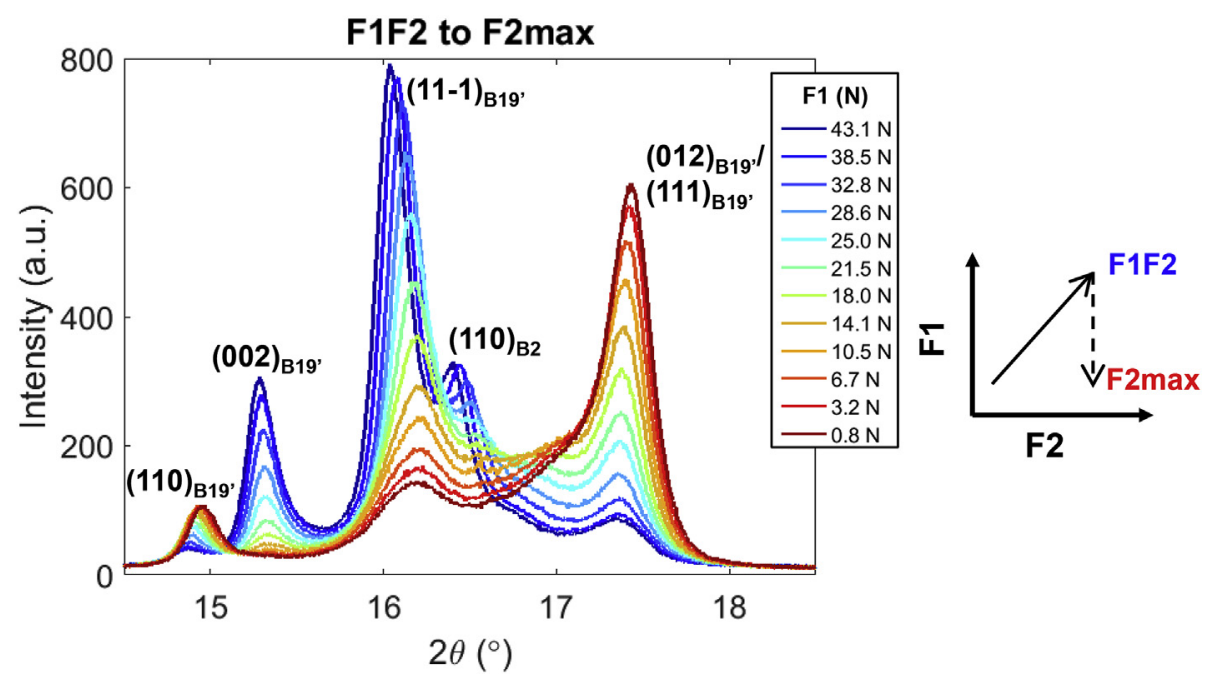

Fig. 13. The change in the martensite footprint induced by the load path change from F1F2 (blue) to F2max (red). 
the diffraction peaks during unloading F1. The intensities of the martensitic peaks $\left(\begin{array}{lll}0 & 0 & 2\end{array}\right)_{\mathrm{B} 19^{\prime}}$ and $\left(\begin{array}{lll}1 & 1 & -1\end{array}\right)_{\mathrm{B} 19^{\prime}}$ reduce and the peak positions change to higher $2 \theta$ values, demonstrating that the unloading changes the VF1F2 variants to VF2 and put the remaining VF1F2 under strain. Based on [53,54], one can assume that during this process: (1) VF1F2 reorients/detwins into VF2 (denoted as VF1F2 - > VF2 in Fig. 12) and (2) the remaining VF1F2 deform by dislocations (denoted as VF1F2 + dislocations in Fig. 12). Furthermore, during this unloading, it is also observed that the $\left(\begin{array}{lll}1 & 1 & 0\end{array}\right)_{\mathrm{B} 2}$ peak reduces its intensity, implying that VF2 variants are formed from the austenite retained at F1F2. The cruciform is fully unloaded after unloading F2. As Fig. 11 shows, the material transforms fully back into the austenite phase after a low number of cycles. Based on Fig. 12, SQ cycling involves more steps where dislocations can accumulate, therefore the chance of retaining VF1 and VF1F2 variants increases. After higher number of cycles, the retained martensite peaks, $\left(\begin{array}{lll}0 & 0 & 2\end{array}\right)_{\mathrm{B} 19^{\prime}}$ and $\left(\begin{array}{lll}1 & 1 & -1\end{array}\right)_{\mathrm{B} 19^{\prime}}$, are a combination of VF1 and VF1F2 footprints (see Fig. 11).

Compared to the load-path-change cycling (TR and SQ), the monotonic UN cycling proceeds mainly with the forward and backward transformation of the favorable variants (VF1) and results in significantly lower broadening as shown in Fig. 10. This result suggests that the accumulation of dislocations solely from the forward and backward martensitic transformation is much less than the deformation of the martensite during load path changes.

\section{Conclusions}

Combining the cruciform multiaxial mechanical tests and insitu synchrotron X-ray diffraction, the deformation and degradation of a commercial superelastic NiTi alloy (Memry $\mathrm{GmbH}$ ) under multiaxial mechanical cycling are studied. The decrease in the critical force for both R-phase and B19' martensitic transformation, the austenite peak broadening and the retained martensite are discussed in terms of the accumulation of dislocations induced by mechanical cycling. Multiaxial cycling (SQ TR and EQ) leads to significantly more accumulation of dislocations and faster degradation than uniaxial cycling (UN). The degradation of the material properties shows a strong dependency on the load path. Due to the strong crystallographic texture $(<1 \quad 1 \quad 1>/ / \mathrm{ND})$ of the austenite phase, EQ cycling accumulates more dislocations than UN cycling. Comparing to monotonic loading, SQ and TR create more dislocations due to the deformation of the martensitic variants upon changing the load path. In summary, texture, loading and unloading path play important roles in the degradation of the microstructure. Since medical devices are made of wires and tubes, tuning the microstructural texture to the design of the device could offer a path for optimization.

\section{Acknowledgment}

W-NH, EP, MS and HVS acknowledge the European Research Council for the ERC advanced Grant MULTIAX (339245), Dr. M. Diserens (micropat SA, Renens) for the extensive discussion of the ECMM sample preparation and Dr. R. Brönnimann (EMPA, Dübendorf) for the assistance in the sample preparation with the picosecond laser.

\section{Appendix A. Supplementary data}

Supplementary data to this article can be found online at https://doi.org/10.1016/j.actamat.2019.01.047.

\section{References}

[1] Y. Kudoh, M. Tokonami, S. Miyazaki, K. Otsuka, Crystal structure of the martensite in $\mathrm{Ti}-49.2$ at.\% Ni alloy analyzed by the single crystal X-ray diffraction method, Acta Metall. 33 (11) (1985) 2049-2056.

[2] K. Otsuka, X. Ren, Physical metallurgy of Ti-Ni-based shape memory alloys, Prog. Mater. Sci. 50 (5) (2005) 511-678.

[3] T. Duerig, A. Pelton, D. Stöckel, An overview of nitinol medical applications, Mater. Sci. Eng., A 273-275 (1999) 149-160.

[4] A. Mehta, X.Y. Gong, V. Imbeni, A.R. Pelton, R.O. Ritchie, Understanding the deformation and fracture of nitinol endovascular stents using In Situ synchrotron X-ray microdiffraction, Adv. Mater. 19 (9) (2007) 1183-1186.

[5] G. Kang, D. Song, Review on structural fatigue of NiTi shape memory alloys: pure mechanical and thermo-mechanical ones, Theor. Appl. Mech. Lett. 5 (6) (2015) 245-254.

[6] L. Orgeas, D. Favier, Non-symmetric tension-compression behaviour of NiTi alloy, J. Phys. IV 5 (C8) (1995) 605-610.

[7] K. Jacobus, H. Sehitoglu, M. Balzer, Effect of stress state on the stress-induced martensitic transformation in polycrystalline Ni-Ti alloy, Metall. Mater. Trans. 27 (10) (1996) 3066-3073.

[8] R. Plietsch, K. Ehrlich, Strength differential effect in pseudoelastic NiTi shape memory alloys, Acta Mater. 45 (6) (1997) 2417-2424.

[9] J.M. McNaney, V. Imbeni, Y. Jung, P. Papadopoulos, R.O. Ritchie, An experimental study of the superelastic effect in a shape-memory Nitinol alloy under biaxial loading, Mech. Mater. 35 (10) (2003) 969-986.

[10] W.-N. Hsu, E. Polatidis, M. Šmíd, N. Casati, S. Van Petegem, H. Van Swygenhoven, Load path change on superelastic NiTi alloys: in situ synchrotron XRD and SEM DIC, Acta Mater. 144 (2018) 874-883.

[11] G. Eggeler, E. Hornbogen, A. Yawny, A. Heckmann, M. Wagner, Structural and functional fatigue of NiTi shape memory alloys, Mater. Sci. Eng., A 378 (1) (2004) 24-33.

[12] M.J. Mahtabi, N. Shamsaei, M.R. Mitchell, Fatigue of Nitinol: the state-of-theart and ongoing challenges, J. Mech. Behav. Biomed. Mater. 50 (2015) $228-254$.

[13] K.N. Melton, O. Mercier, Fatigue of NITI thermoelastic martensites, Acta Metall. 27 (1) (1979) 137-144.

[14] S. Miyazaki, T. Imai, Y. Igo, K. Otsuka, Effect of cyclic deformation on the pseudoelasticity characteristics of Ti-Ni alloys, Metall. Trans. A 17 (1) (1986) 115-120.

[15] K. Gall, H. Sehitoglu, Y.I. Chumlyakov, I.V. Kireeva, Pseudoelastic cyclic stressstrain response of over-aged single crystal Ti-50.8at\%Ni, Scripta Mater. 40 (1) (1998) 7-12.

[16] E. Polatidis, N. Zotov, E. Bischoff, E.J. Mittemeijer, The effect of cyclic tensile loading on the stress-induced transformation mechanism in superelastic NiTi alloys: an in-situ X-ray diffraction study, Scripta Mater. 100 (2015) 59-62.

[17] N. Zotov, M. Pfund, E. Polatidis, A.F. Mark, E.J. Mittemeijer, Change of transformation mechanism during pseudoelastic cycling of NiTi shape memory alloys, Mater. Sci. Eng., A 682 (2017) 178-191.

[18] A.M. Condó, F.C. Lovey, J. Olbricht, C. Somsen, A. Yawny, Microstructural aspects related to pseudoelastic cycling in ultra fine grained $\mathrm{Ni}-\mathrm{Ti}$, Mater. Sci. Eng., A 481-482 (2008) 138-141.

[19] A. Condo, C. Somsen, J. Olbricht, G. Eggeler, A. Dlouhy, R-phase Stabilization in Ultra-fine Grain NiTi Wires after Mechanical Cycling, Esomat 2009 - 8th European Symposium on Martensitic Transformations, 2009.

[20] B. Strnadel, S. Ohashi, H. Ohtsuka, S. Miyazaki, T. Ishihara, Effect of mechanical cycling on the pseudoelasticity characteristics of Ti-Ni and Ti-Ni-Cu alloys, Mater. Sci. Eng., A 203 (1) (1995) 187-196.

[21] H. Sehitoglu, R. Anderson, I. Karaman, K. Gall, Y. Chumlyakov, Cyclic deformation behavior of single crystal NiTi, Mater. Sci. Eng., A 314 (1) (2001) 67-74.

[22] S. Mao, X. Han, M.H. Wu, Z. Zhang, F. Hao, D. Liu, Y. Zhang, B. Hou, Effect of cyclic loading on apparent young's modulus and critical stress in nanosubgrained superelastic NiTi shape memory alloys, Mater. Trans. (3) (2006) $735-741$.

[23] X.M. Wang, Y.F. Wang, Z.Z. Lu, C.H. Deng, Z.F. Yue, An experimental study of the superelastic behavior in NiTi shape memory alloys under biaxial proportional and non-proportional cyclic loadings, Mech. Mater. 42 (3) (2010) 365-373.

[24] C. Maletta, E. Sgambitterra, F. Furgiuele, R. Casati, A. Tuissi, Fatigue properties of a pseudoelastic NiTi alloy: strain ratcheting and hysteresis under cyclic tensile loading, Int. J. Fatig. 66 (2014) 78-85.

[25] S. Jaeger, B. Maaß, J. Frenzel, M. Schmidt, J. Ullrich, S. Seelecke, A. Schütze, O. Kastner, G. Eggeler, On the widths of the hysteresis of mechanically and thermally induced martensitic transformations in Ni-Ti-based shape memory alloys, Int. J. Mater. Res. 106 (10) (2015) 1029-1039.

[26] K. Gall, H. Maier, Cyclic deformation mechanisms in precipitated NiTi shape memory alloys, Acta Mater. 50 (18) (2002) 4643-4657.

[27] R. Delville, B. Malard, J. Pilch, P. Sittner, D. Schryvers, Transmission electron microscopy investigation of dislocation slip during superelastic cycling of Ni-Ti wires, Int. J. Plast. 27 (2) (2011) 282-297.

[28] B. Malard, J. Pilch, P. Sittner, R. Delville, C. Curfs, In situ investigation of the fast microstructure evolution during electropulse treatment of cold drawn NiTi wires, Acta Mater. 59 (4) (2011) 1542-1556.

[29] P. Sedmák, P. Šittner, J. Pilch, C. Curfs, Instability of cyclic superelastic 
deformation of NiTi investigated by synchrotron X-ray diffraction, Acta Mater. 94 (2015) 257-270.

[30] H. Tobushi, Y. Shimeno, T. Hachisuka, K. Tanaka, Influence of strain rate on superelastic properties of TiNi shape memory alloy, Mech. Mater. 30 (2) (1998) 141-150.

[31] H. Soul, A. Isalgue, A. Yawny, V. Torra, F.C. Lovey, Pseudoelastic fatigue of NiTi wires: frequency and size effects on damping capacity, Smart Mater. Struct. 19 (8) (2010).

[32] D. Song, G. Kang, O. Kan, C. Yu, C. Zhang, Non-proportional multiaxial transformation ratchetting of super-elastic NiTi shape memory alloy: experimental observations, Mech. Mater. 70 (2014) 94-105.

[33] H. Khodaei, P. Terriault, Experimental validation of shape memory material model implemented in commercial finite element software under multiaxial loading, J. Intell. Mater. Syst. Struct. 29 (14) (2018) 2954-2965.

[34] E. Polatidis, W.N. Hsu, M. Šmíd, H. Van Swygenhoven, A high resolution digital image correlation study under multiaxial loading, Exp. Mech. (2018). https:// doi.org/10.1007/s11340-018-00443-6.

[35] S. Van Petegem, A. Guitton, M. Dupraz, A. Bollhalder, K. Sofinowski, M.V. Upadhyay, H. Van Swygenhoven, A miniaturized biaxial deformation rig for in situ mechanical testing. Exp. Mech. 57 (4) (2017) 569-580.

[36] P.R. Willmott, D. Meister, S.J. Leake, M. Lange, A. Bergamaschi, M. Boge, M. Calvi, C. Cancellieri, N. Casati, A. Cervellino, Q. Chen, C. David, U. Flechsig, F. Gozzo, B. Henrich, S. Jaggi-Spielmann, B. Jakob, I. Kalichava, P. Karvinen, J. Krempasky, A. Ludeke, R. Luscher, S. Maag, C. Quitmann, M.L. ReinleSchmitt, T. Schmidt, B. Schmitt, A. Streun, I. Vartiainen, M. Vitins, X. Wang, R. Wullschleger, The materials science beamline upgrade at the Swiss light source, J. Synchrotron Radiat. 20 (5) (2013) 667-682.

[37] A.P. Hammersley, S.O. Svensson, M. Hanfland, A.N. Fitch, D. Hausermann, Two-dimensional detector software: from real detector to idealised image or two-theta scan, High Pres. Res. 14 (4-6) (1996) 235-248.

[38] D.M. Norfleet, P.M. Sarosi, S. Manchiraju, M.F.X. Wagner, M.D. Uchic, P.M. Anderson, M.J. Mills, Transformation-induced plasticity during pseudoelastic deformation in Ni-Ti microcrystals, Acta Mater. 57 (12) (2009) 3549-3561.

[39] T. Simon, A. Kröger, C. Somsen, A. Dlouhy, G. Eggeler, On the multiplication of dislocations during martensitic transformations in NiTi shape memory alloys, Acta Mater. 58 (5) (2010) 1850-1860.

[40] M.L. Bowers, X. Chen, M. De Graef, P.M. Anderson, M.J. Mills, Characterization and modeling of defects generated in pseudoelastically deformed NiTi microcrystals, Scripta Mater. 78-79 (2014) 69-72.

41] J. Hurley, A.M. Ortega, J. Lechniak, K. Gall, H.J. Maier, Structural evolution during the cycling of NiTi shape memory alloys, Z. Metallkd. 94 (5) (2003) 547-552.

[42] A.R. Pelton, Nitinol fatigue: a review of microstructures and mechanisms, J. Mater. Eng. Perform. 20 (4-5) (2011) 613-617.

[43] S. Miyazaki, K. Otsuka, Deformation and transition behavior associated with the R-phase in Ti-Ni alloys, Metall. Trans. A 17 (1) (1986) 53-63.

[44] X. Ren, N. Miura, J. Zhang, K. Otsuka, K. Tanaka, M. Koiwa, T. Suzuki, Y.I. Chumlyakov, M. Asai, A comparative study of elastic constants of Ti-Nibased alloys prior to martensitic transformation, Mater. Sci. Eng., A 312 (1) (2001) 196-206.

[45] X.B. Wang B. Verlinden, J. Van Humbeeck, R-phase transformation in NiTi alloys, Mater. Sci. Technol. 30 (13) (2014) 1517-1529.

[46] T.J. Lim, D.L. McDowell, Path dependence of shape memory alloys during cyclic loading, J. Intell. Mater. Syst. Struct. 6 (6) (1995) 817-830.

[47] A. Yawny, M. Sade, G. Eggeler, Pseudoelastic cycling of ultra-fine-grained NiT shape-memory wires, Zeitschrift Fur Metallkunde 96 (6) (2005) 608-618.

48] S. Van Petegem, J. Wagner, T. Panzner, M.V. Upadhyay, T.T.T. Trang, H. Van Swygenhoven, In-situ neutron diffraction during biaxial deformation, Acta Mater. 105 (2016) 404-416.

[49] H. Sehitoglu, I. Karaman, R. Anderson, X. Zhang, K. Gall, H.J. Maier Y. Chumlyakov, Compressive response of NiTi single crystals, Acta Mater. 48 (13) (2000) 3311-3326.

[50] P. Sittner, V. Novák, Anisotropy of martensitic transformations in modeling of shape memory alloy polycrystals, Int. J. Plast. 16 (10) (2000) 1243-1268.

[51] J. Pfetzing-Micklich, R. Ghisleni, T. Simon, C. Somsen, J. Michler, G. Eggeler, Orientation dependence of stress-induced phase transformation and dislocation plasticity in NiTi shape memory alloys on the micro scale, Mater. Sci. Eng., A 538 (2012) 265-271.

[52] K. Gall, T.J. Lim, D.L. McDowell, H. Sehitoglu, Y.I. Chumlyakov, The role of intergranular constraint on the stress-induced martensitic transformation in textured polycrystalline NiTi, Int. J. Plast. 16 (10) (2000) 1189-1214.

[53] Y. Liu, Z.L. Xie, J. Van Humbeeck, L. Delaey, Effect of texture orientation on the martensite deformation of NiTi shape memory alloy sheet, Acta Mater. 47 (2) (1999) 645-660.

[54] Y. Liu, Z. Xie, J. Van Humbeeck, L. Delaey, Y. Liu, On the deformation of the twinned domain in Niti shape memory alloys, Philos. Mag. A 80 (8) (2000) 1935-1953. 